\title{
Secondary Adrenal Insufficiency
}

National Cancer Institute

\section{Source}

National Cancer Institute. Secondary Adrenal Insufficiency. NCI Thesaurus. Code C62602.

A hormonal disorder that occurs when lack of corticotropin-releasing hormone (CRH) secretion from the hypothalamus or adrenocorticotropic hormone (ACTH) secretion from the pituitary is responsible for hypofunction of the adrenal cortex. 